\title{
Wie modern war das Kaiserreich?
}

\author{
Das Beispiel der Schule
}

Thomas Nipperdey

(W)

Springer Fachmedien Wiesbaden GmbH 
Der Vortrag wurde am 24. April 1986 in Düsseldorf gehalten.

CIP-Kurztitelaufnahme der Deutschen Bibliothek

Nipperdey, Thomas:

Wie modern war das Kaiserreich? d. Beispiel d. Schule/Thomas Nipperdey.

(Gerda-Henkel-Vorlesung)

ISBN 978-3-531-11958-8 ISBN 978-3-663-14260-7 (eBook)

DOI $10.1007 / 978-3-663-14260-7$

(C) 1986 by Springer Fachmedien Wiesbaden

Ursprünglich erschienen bei Westdeutscher Verlag GmbH, Opladen 1986

Softcover reprint of the hardcover 1st edition 1986 